\title{
Management of Pulmonary Artery Aneurysm and Intracardiac Thrombus in a Young Male With Behçet's Disease
}

\author{
Özgür Ulaş ÖZCAN, Adalet GÜRLEK, Görkem YILDIZ, İrem Müge AKBULUT, \\ Eralp TUTAR, Çetin EROL
}

Department of Cardiology, Medical Faculty of Ankara University, Ankara, Turkey

\begin{abstract}
Pulmonary artery aneurysm associated with intracardiac thrombus is a rare complication of Behçet's disease. In this article, we report a 26-yearold male admitted with massive hemoptysis. Pulmonary computed tomography angiogram demonstrated pulmonary artery aneurysm with thrombus. Echocardiography revealed a mobile right ventricular thrombus. The patient was treated with corticosteroids, cyclophosphamide, azathioprine, and colchicine without anticoagulant therapy. During follow-up, pulmonary artery aneurysm regressed, and no bleeding or thromboembolic event was observed.

Keywords: Behçet's disease; intracardiac thrombus; pulmonary artery aneurysm.
\end{abstract}

Behçet's disease (BD) is a multi-systemic and chronic inflammatory disorder which is frequently seen in Mediterranean, Middle Eastern, and Far Eastern countries. It is characterized by recurrent oral aphthous ulcers, genital ulcers, uveitis, and skin lesions. Etiology of $\mathrm{BD}$ is uncertain, however, genetic predisposition (human leukocyte antigen-B51) is also thought to play a role. Vascular involvement which is encountered in $25-30 \%$ of patients is the leading cause of death. ${ }^{1}$ Involvement of arterial system is infrequent compared with venous system. Inflammation of vasa vasorum may cause aneurysm formation, most commonly in the abdominal aorta. Thoracic aorta and pulmonary arteries are rarely affected. ${ }^{2}$ Nevertheless, the most common cause of pulmonary artery aneurysm (PAA) is $\mathrm{BD} .^{3}$

Intracardiac thrombus formation is an unusual complication of $\mathrm{BD},{ }^{4}$ however, patients with PAA often have concomitant venous and intracardiac thrombi. ${ }^{5}$ This condition creates therapeutic dilemma because of the risk of massive hemoptysis and emboli.

\section{CASE REPORT}

A 26-year-old man diagnosed with $\mathrm{BD}$ was hospitalized with cough, dyspnea, hemoptysis, and weight loss. Physical examination was non-specific except for high fever $\left(38.2{ }^{\circ} \mathrm{C}\right)$, tachycardia, a painful $2 \times 1 \mathrm{~cm}$ genital ulcer, and acneiform skin lesions on the back. Blood tests demonstrated an inflammatory response with elevated white blood cells $\left(14.1 \times 10^{9} / \mathrm{L}\right)$, and high C-reactive protein level $(88 \mathrm{mg} / \mathrm{L})$. Diagnosis of BD was made with the presence of oral ulcer, recurrent genital ulcers, and positive skin pathergy test two years ago.

Chest X-ray showed left parahilar opacity (Figure 1). Pulmonary computed tomography (CT) angiogram revealed PAA with thrombus (Figure 2a). Bronchoscopy revealed no origin of bleeding. Echocardiography demonstrated mobile thrombus in the right ventricle (Figure 3a). Blood and urine cultures were sterile. Venereal Disease Research Laboratory test, tuberculosis tests, human immunodeficiency virus serology, antiphospholipid antibodies, anti-nuclear 


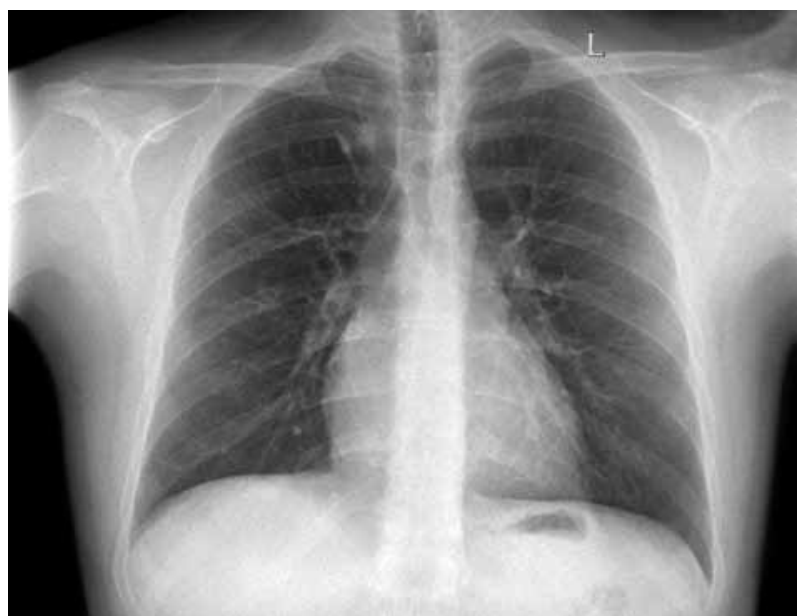

Figure 1. Chest $X$ ray showing left parahilar opacity.

antibodies, and anti-neutrophil cytoplasmic antibodies were negative. Hereditary coagulation thrombophilic factors were normal.

The patient was treated with pulse steroid (intravenous methyl prednisolon $1 \mathrm{~g} / \mathrm{d}$ for three days), intravenous cyclophosphamide $(1 \mathrm{mg} / \mathrm{kg} / \mathrm{d})$, peroral azathioprine $(125 \mathrm{mg} / \mathrm{d})$ and peroral colchicine $0.5 \mathrm{mg} / \mathrm{d}$. Peroral prednison was given after intravenous methyl prednisolon. Anticoagulation therapy was not administered. Patient was followed-up to one year. Reevaluation with pulmonary CT angiograms and echocardiograms demonstrated a remarkable regression of PAAs, and organization of intracardiac thrombus (Figures $2 \mathrm{~b}$ and $3 \mathrm{~b}$, respectively). Currently, the patient is in a stable condition without hemoptysis or embolic event.

\section{DISCUSSION}

The concept 'vasculo-Behçet' is suggested to describe the cases in which vascular complications dominate the clinical picture. It is more common in men than in women. Early diagnosis and aggressive treatment is essential due to the unfavorable disease progress. Pulmonary artery aneurysm formation is the most lethal complication of $\mathrm{BD}$. The pathologic feature of PAA is the inflammation of the vasa vasorum of pulmonary arteries which causes ischemia and weakening of vessel wall. Moreover, these lesions may open in the bronchi and cause massive hemoptysis. ${ }^{6}$ Patients with BD are more prone to hemorrhagic complications of anticoagulation therapy due to common coincidence of aneurysms. Thrombus formation in $\mathrm{BD}$ is not a primary coagulation abnormality. Thrombi are caused by the inflammation of the vessel wall, and often adhered to wall having less tendency to embolize. ${ }^{7}$ So, the incidence of pulmonary thromboembolism is very low in BD. ${ }^{6}$ The indication of anticoagulation therapy is not clearly shown in $\mathrm{BD}$ and venous thrombus. ${ }^{8}$ Treatment of PAA in BD involves combination of anti-inflammatory, and immunosuppressive agents. Prednisone, cyclophosphamide, azathioprine, cyclosporine, and tacrolimus are commonly used agents. Furthermore, tumor necrosis factor-alpha antagonist infliximab is a new agent for treatment
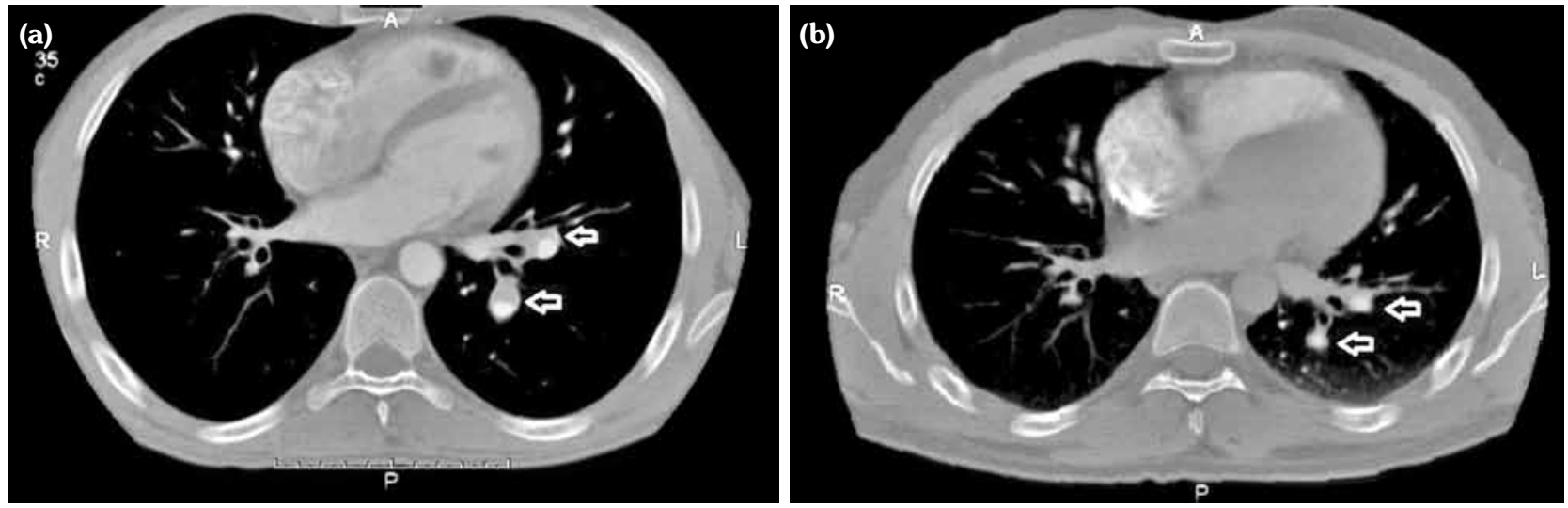

Figure 2. (a) Axial contrast-enhanced computed tomography scan shows aneurysm of left upper lobe pulmonary artery (arrows) accompanied by mural thrombus. (b) Follow-up computed tomography scan demonstrates regression of pulmonary artery aneurysms (arrows) one year later. 


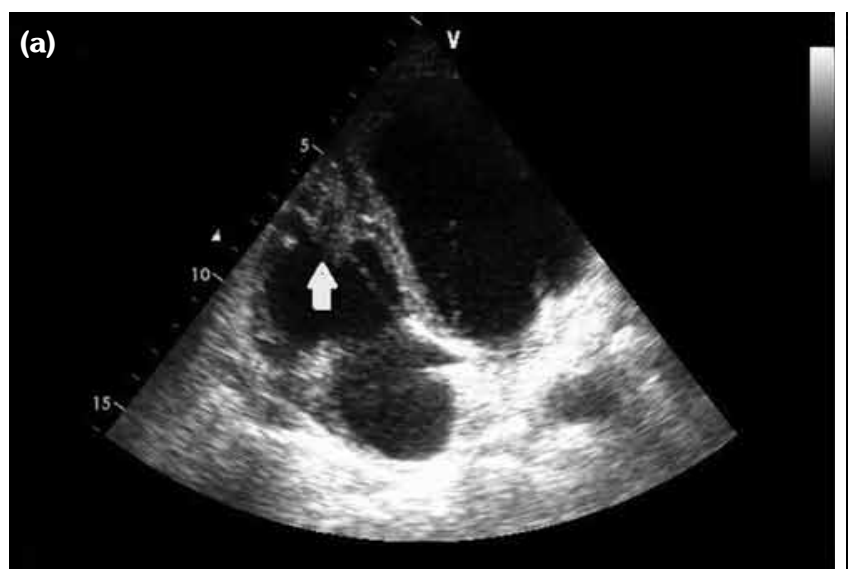

Figure 3. (a) Hypoechoic, soft, mobile thrombus in the apex of right ventricle (arrow). (b) Follow-up echocardiogram revealed hyperechoic and organized immobile thrombus in the right ventricle (arrow).

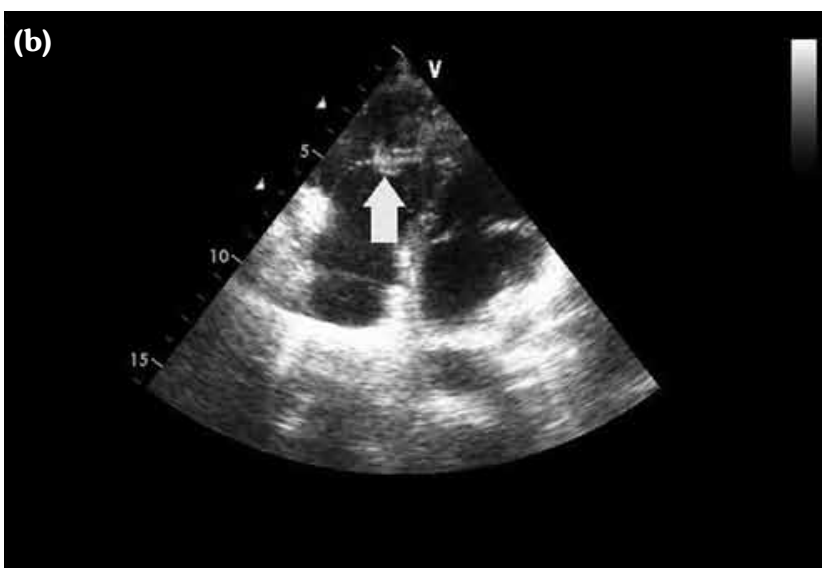

of PAA in BD.6,9 The mainstay of treatment in $\mathrm{BD}$ is immunosuppressive therapy in patients with PAAs and intracardiac thrombus. Although there may be bleeding risks with anticoagulant therapy for patients with aneurysmal dilatation of pulmonary vessels, ${ }^{10}$ short-term anticoagulation may be used in patients without hemoptysis. ${ }^{11}$ Additionally, endovascular embolization may be a therapy of choice for treatment-resistant hemoptysis. ${ }^{10}$

This case is an example demonstrating the difficulty of management of vasculo-Behçet patients with concurrent bleeding and thrombotic complications. We were able to manage our patient without any thromboembolic event, or need for endovascular embolization or emergent surgery for bleeding episode. In conclusion, this case supported an anti-inflammatory and immunosuppressive therapy without anticoagulation for $\mathrm{BD}$ with intracardiac thrombus and PAA.

\section{Declaration of conflicting interests}

The authors declared no conflicts of interest with respect to the authorship and/or publication of this article.

\section{Funding}

The authors received no financial support for the research and/or authorship of this article.

\section{REFERENCES}

1. Ceylan N, Bayraktaroglu S, Erturk SM, Savas R, Alper $\mathrm{H}$. Pulmonary and vascular manifestations of Behcet disease: imaging findings. AJR Am $\mathrm{J}$ Roentgenol 2010;194:W158-64.

2. Park JH, Chung JW, Joh JH, Song SY, Shin SJ, Chung KS, et al. Aortic and arterial aneurysms in behçet disease: management with stent-grafts--initial experience. Radiology 2001;220:745-50.

3. Celenk C, Celenk P, Akan H, Başoğlu A. Pulmonary artery aneurysms due to Behçet's disease: MR imaging and digital subtraction angiography findings. AJR Am J Roentgenol 1999;172:844-5.

4. Khammar Z, Berrady R, Boukhrissa A, Lamchachti L, Amrani K, Rabhi $S$, et al. Intracardiac thrombosis in Behçet disease: clinical presentation and outcome of three cases. J Mal Vasc 2011;36:270-3.

5. Atzeni F, Sarzi-Puttini P, Doria A, Boiardi L, Pipitone $\mathrm{N}$, Salvarani C. Behçet's disease and cardiovascular involvement. Lupus 2005;14:723-6.

6. Calamia KT, Schirmer M, Melikoglu M. Major vessel involvement in Behçet's disease: an update. Curr Opin Rheumatol 2011;23:24-31.

7. Schreiber BE, Noor N, Juli CF, Haskard DO. Resolution of Behçet's syndrome associated pulmonary arterial aneurysms with infliximab. Semin Arthritis Rheum 2011;41:482-7.

8. Mehta P, Laffan M, Haskard DO. Thrombosis and Behçet's syndrome in non-endemic regions. Rheumatology (Oxford) 2010;49:2003-4.

9. Endo LM, Rowe SM, Romp RL, Buckmaster MA, Atkinson TP. Pulmonary aneurysms and intracardiac thrombi due to Behçet's disease in an AfricanAmerican adolescent with oculocutaneous albinism. Clin Rheumatol 2007;26:1537-9.

10. El Houari T, Oukerraj L, Ghzaiel L, Fellat I, Azeroual $\mathrm{M}$, Serraj K, et al. Management of Behçet disease with multiple complications. Hellenic J Cardiol 2009;50:420-2.

11. Vivante A, Bujanover Y, Jacobson J, Padeh S, Berkun Y. Intracardiac thrombus and pulmonary aneurysms in an adolescent with Behçet disease. Rheumatol Int 2009;29:575-7. 